\title{
Escuchar a Kay. Nuestras prácticas son producto de otra parte
}

\section{Listening to Kay. Our practices are product of another place}

\author{
Paulina E. Varas \\ Universidad Andrés Bello \\ paulina.varas.a@unab.cl \\ Francisco Godoy Vega \\ Universidad Autónoma de Madrid \\ francisco.de.godoy@gmail.com
}

\section{Resumen}

El presente artículo se enfoca en el audio de un archivo de casetes de la artista Luz Donoso sobre un par de sesiones del seminario sobre Walter Benjamin que dictó Ronald Kay en el Goethe Institut de Santiago de Chile en 1981. La forma de transcripción intenta componer el escenario de la escucha y poner en valor este tipo de fuentes documentales orales en el estudio de las artes de los años ochenta en Chile.

Palabras clave:Walter Benjamin, fuentes documentales orales, arte chileno.

\section{Abstract}

This article focuses on the audio of a cassette archive of the artist Luz Donoso on a couple of sessions of the Walter Benjamin seminar that Ronald Kay dictated at the Goethe Institut of Santiago de Chile in 1981. The transcription form attempts to compose the listening scenario and putting value to this type of oral documentary sources in the study of the arts of the eighties in Chile.

Keywords:Walter Benjamin, oral documentary, chilean art. 
El poeta, teórico y editor Ronald Kay desarrolló en 1981 un seminario en el Goethe Institut de Santiago donde se leyeron textos de Walter Benjamin traducidos por él mismo. Hoy podemos escuchar esos audios registrados en una máquina grabadora de casetes, gracias a que la artista chilena Luz Donoso ${ }^{1}$ grabó y conservó esos casetes en su archivo, así como una centena de otras actividades del Chile de la época. En este texto presentamos una forma de escucha que pretende no solo poner en valor un material documental oral inédito, sino que queremos pensar formas en que pueda ser escuchado y transcrito, maneras de compartirlo para futuras elaboraciones. Presentamos en este texto una sesión sobre la lectura de párrafos del texto "La obra de arte en la época de su reproductibilidad técnica" escrito por Benjamin en 1932 y traducido por Kay en los años sesenta. La escucha en sí misma presenta una serie de posibilidades para ser transcrita e incluso traducida subjetivamente como material documental, así decidimos no editar en gran medida lo hablado, ser una especie de "testigo mudo" en la medida de que esta propia imposibilidad activa otras formas de comportamiento frente a lo escuchado. No haber estado allí permite transitar otras formas de comprensión frente a lo que se escucha y sobre todo imaginar las formas en que todo lo que se escucha transcurrió. De esta manera, pensamos también en los cuerpos que estaban allí, las voces que dan sentido a la escucha, en este caso es la de Kay la que está más presente, junto a murmullos o preguntas de los asistentes. En sí misma, esta escucha es un escenario por imaginar, por componer o recomponer, que se va construyendo en base a una serie de posibles acciones.

Escuchar en vivo, escuchar en persona. Escucha subjetiva o una escucha como parte del buen vivir andino, en el cual el "Suma Ist' añ" o "Saber escuchar" implica "no solo es escuchar con los oídos; es percibir, sentir, escuchar con todo nuestro cuerpo; si todo vive, todo habla también". En ese sentido vital escuchamos mientras habla, le escuchamos dialogar y estar allí mismo conversando con otros, escuchando preguntas, comentarios, dificultades de entrar en algunos temas, formas de explicar, dejar de entender el sentido mientras la voz se aleja de la máquina que graba, luego vuelve y con el sonido, el sentido. Escucharle hoy día aporta otra capa de sentido, un destiempo que conecta experiencias subterráneas, siendo una especie de testigo mudo e invisible que escribe, mientras escucha. El material es un audio de personas que comparten una lectura colectiva; pensamos que leer a Benjamin en colectivo en medio de la dictadura cívico-militar en 1981, se transforma en un episodio de resistencia, un espacio de cuidado mutuo, una manera de no enloquecer, mantener cierta

1 Luz Donoso (Santiago 1921-2008) artista chilena. En 1956 integra el “Taller 99” inicialmente tomando cursos de dibujo y grabado con Nemesio Antúnez. Desde 1974 fue miembro fundadora del T.A.V. (Taller de Artes Visuales) en Santiago, donde comparte con una serie de artistas y críticos chilenos en una intensa etapa de activación crítica y política del arte. Durante los años 80 s realiza y es parte de un sinnúmero de acciones de arte en el espacio público que vienen activadas desde ideas desarrolladas en los años precedentes, y desde 1982 comienza a proponer que su trabajo se enmarca en la idea de "Trabajos críticos dentro y fuera del arte" a propósito de su intensa vinculación con organismos sociales y de derechos humanos en el contexto de la dictadura militar en conjunto y en colaboración con otros artistas. Ver: Varas, Paulina "Una acción de otro es una obra de la Luz Donoso" CEAC/UC Santiago, 2011. 
cordura. Esa resistencia traspasa un momento específico y se sitúa en este momento presente cuando escuchamos y aporta un sentido actualizado.

La máquina grabadora de audios de casetes que portaba la artista Luz Donoso por muchos lugares del escenario político y cultural de Chile en los años setenta y ochenta, presenta la posibilidad de que haya quedado otro tipo de registro de esos lugares que los que ya conocemos. En investigaciones de los últimos diez años en Chile sobre los años sesenta y ochenta desarrollada por diversos investigadores, se han utilizado una serie de fuentes documentales, destacándose acá, desde el ámbito institucional, el Centro de Documentación de las Artes (CEDOC). Este inició el concurso de ensayos de investigación que ha pretendido contribuir con estudios sobre las prácticas y discursos de los años setenta y ochenta en Chile, poniendo en valor los documentos que son parte de su colección en conexión con otras fuentes. En acuerdo con la editorial chilena Lom Ediciones, se han realizado hasta la fecha siete convocatorias con importantes contribuciones a la historia de ese período. Además, el CEDOC implementó un archivo digital con fuentes documentales que son accesibles desde la web de manera gratuita, así como lo han hecho otras iniciativas institucionales como la plataforma memoriachilena.cl o desde el ámbito extra institucional la Red de Conceptualismos del Sur con el archivo digital archivosenuso.org, los cuales contienen fuentes documentales que aportan a la investigación. En estos casos se cuenta con fuentes impresas, fotográficas y en algunos casos videográficas.

Por otro lado, otro tipo de fuentes utilizadas han sido las entrevistas con protagonistas de la época, y ejemplo de ello son la serie de libros Filtraciones que ha publicado el académico de la Universidad de Chile Federico Galende. Se trata de tres tomos: Filtraciones I. Conversaciones sobre arte en Chile (de los 60s a los 80s); Filtraciones II. Conversaciones sobre arte en Chile (de los 80s a los 90s); Filtraciones III. Conversaciones sobre arte en Chile (de los 90s al 2000). Estos han sido un aporte en relación a las fuentes documentales orales de protagonistas y sucesos de las épocas señaladas en base al recuerdo que ellos tienen de varios acontecimientos.

En el caso de archivos orales conservados en casetes de audio es importante señalar aquellos que el historiador y crítico Gaspar Galaz conservó del "Encuentro de artistas del Cono Sur" realizado en 1972 en Chile y que fueron transcritos y editados en el número 2 de los Cuadernos de la Escuela de Arte de la Universidad Católica en Chile.

Este otro tipo de fuentes que mencionamos y que son parte de este archivo oral de casetes de audio que la artista Luz Donoso fue construyendo durante más de veinte años, se instala en otro lugar del registro institucional, y está más cercano a un proceso tanto de su trabajo como artista y activista, así como a una profunda y anticipada reflexión sobre los archivos de arte, las fuentes documentales para la historia y la memoria cultural y política.

Para Luz Donoso, los casetes que conservó son como ramificaciones de su obra artística, unas derivaciones tecnológicas de los grabados con los que ella inició su camino por el arte. Formas de implicarse totalmente, registrar la vida y guardar el sonido 
de los encuentros se constituyen en sinuosidades que permiten revisitar, componer, recomponer y proyectar. La artista se preocupó que ese material que iba recogiendo de la vida político-cultural chilena estuviera disponible para futuras elaboraciones, como recuerda el artista Hernán Parada:

Luz era una mujer que gustaba de registrar y grabar todo lo que podía interesarle y ser material de su constante capacidad creadora. Me decía "grabemos esto, así después en casa puedo re-escuchar el material y escribir acerca de ello". Ella vivía entonces con su madre, en una gran casona en un barrio hermoso en la calle Lota. Ella mencionaba que había tenido la oportunidad de viajar a la Unión Soviética y Alemania, y que la poca plata que llevó la utilizó para comprar la máquina fotográfica que usábamos y que me prestaba para tomar fotografías. Además, adquirió una filmadora $8 \mathrm{~mm}$, que veíamos y tocábamos, pero que nunca pudimos usar. Principalmente estaba obsesionada con tecnologías que le permitieran grabar el mundo visual o sonoro. (Parada, 11)

La prueba de este interés por las tecnologías de reproducción, según menciona Parada, va a ser la utilización que hará del video en distintas ocasiones y en diferentes obras. Los casetes de audio en este caso, en tanto proyecto artístico de naturaleza archivística, los irá utilizando en ciertas ocasiones como audio de algunos videos.

Para Luz esas cintas de audio no eran solo registro para el futuro, sino que eran presente, donde lo temporal es la acción de registrar y el futuro las relaciones que hipervincula. Así lo dejó inscrito en algunos de sus cuadernos donde iba a la vez registrando sus ideas:

Tengo todas las cintas, como si fuera ayer, las oigo muy rara vez, pero ¡como si fuera ayer! estaban ahí (...) todo está grabado, también grababa por ejemplo la vida cada vez que se iba al cementerio y se gritaban cosas a lo Neruda o en marchas y también las cosas que eran discusiones de arte. ${ }^{2}$

Varias historias pueden ser reconstruidas y reelaboradas a la luz de estos archivos sonoros, en la medida que se dispongan las condiciones de escucha necesarias. Muchas personas creían olvidados estos materiales, pero la artista los guardó silenciosamente, sin que casi nadie supiera que los conservaba todos ${ }^{3}$. Poner en cuestión nuestro saber objetivo, transformarnos en investigadoras sensibles, despojadas de certezas documentales para dejar entrar la incertidumbre, la paradoja, el error. Mezclar nuestros recuerdos con esos audios que escuchamos, afectarnos por algún tipo de memoria punzante. Estos audios ponen en duda algunos de los relatos construidos sobre la

2 Documento inédito, Archivo Luz Donoso.

3 Estos casetes son parte del archivo de Luz Donoso que se conserva en Santiago de Chile por parte de sus familiares. Un proyecto de digitalización de esta colección fue posible gracias al apoyo de la Foundation for Arts Initiatives y la Red Conceptualismos del Sur. 
base de documentación escrita de la historia reciente en Chile, en la medida que son registros de los sucesos que algunas investigadoras hemos intentado reconstruir, llenando algunos vacíos de sentido. Estos audios cuestionan nuestros procesos de investigación y documentación. Se trata de una oportunidad de autocrítica, de resensibilización frente a lo que entendíamos como esos "objetos de estudio". Los audios transportan, llevan a otro sitio. Los casetes de Luz realizan un tipo de apertura respecto a cómo hemos abordado no solo metodológicamente, sino que sensiblemente, estos episodios. Creemos que el proceso de visibilización de prácticas que han sido menos abordadas por historiadores del arte e investigadores en cultura, es un gran avance en la heterogeneidad de las historias. Legados vigentes con los que dialogar, propuestas abiertas por donde entrar de diferentes modos, recuerdos pulsantes que hagan vibrar nuestros cuerpos con el mundo. ${ }^{4}$

Para este artículo nos centraremos específicamente en dos casetes que registran la experiencia del seminario de Ronald Kay sobre Benjamin con un grupo de asistentes del escenario cultural chileno de la época. Presentamos este ejercicio de escucha analítica para poner en valor esta memoria oral y también para dar cuenta de lo importante que se tornan los diversos tipos de fuentes documentales a la hora de abordar el contexto cultural en los años ochenta en Chile. Tratándose de una década signada por la represión política en todos los ámbitos de la vida, las reuniones en pequeños grupos adquirieron formas de cuidado mutuo. Los audios son testigo de la situación misma que se da en la lectura y diálogo con los asistentes, las complejidades y las visiones que en nuestro presente pueden dar lugar a múltiples interpretaciones.

\section{Contexto de Kay en Chile}

Ronald Kay nació en Hamburgo en 1941, hijo de madre chilena que trabajaba en labores consulares en Alemania y de padre soldado alemán que participó en la segunda Guerra Mundial. Estudia dos años de Derecho en la Universidad de Chile y luego en la Universidad de Oxford en 1960. Como poeta comienza en 1962, cuando ingresa a la Facultad de Filosofía de la Universidad de Chile, donde funda la Academia Literaria del Departamento de Castellano y en 1967 publica sus poemas en los Anales de la Universidad de Chile. Kay además de su obra poética, escribió una serie de importantes

4 Acá nos referimos al concepto de "cuerpo vibrátil" que desarrolla Suely Rolnik donde ella señala que esta condición, "nos permite aprehender el mundo en su condición de los campos de fuerzas que nos afectan y se nos hacen presentes en el cuerpo bajo la forma de sensaciones. El ejercicio de esta capacidad está desvinculado de la historia del sujeto y del lenguaje. Con ella, el otro es una presencia viva hecha de una multiplicidad plástica de fuerzas que pulsan en nuestra textura sensible, tornándose así parte de nosotros y de nosotras mismas. Se disuelven aquí las figuras de sujeto y objeto, y con ellas aquello que separa el cuerpo del mundo. Ya en la década de los ochenta (en un libro que ahora ha sido reeditado) llamé "cuerpo vibrátil" a esta segunda capacidad de nuestros órganos de los sentidos en su conjunto. Es nuestro cuerpo como un todo el que tiene este poder de vibración en las fuerzas del mundo". (Ver referencia en bibliografía). 
textos sobre artistas chilenos y de teoría como por ejemplo Del espacio de acá sobre fotografía y la obra de Eugenio Dittborn, que se entrelazará con otras publicaciones de la época. Como señala uno de los autores de este texto, Francisco Godoy:

Lo ocurrido en el ámbito de las publicaciones de arte de los '70 se puede entender como una trama rizomática interconectada, donde cada una fue insertando una serie de problemáticas diferenciadas (lo fragmentario, la letra manuscrita, etc.). Con algunas publicaciones la escena sufriría una fractura en términos de experimentalidad en el libro, así como de la constitución diversa de las propuestas en articulación. Se establecen alianzas y disputas teórico-artísticas con una fuerte presencia y debate del estructuralismo y postestructuralismo francés, el psicoanálisis, la semiótica, el post-marxismo y la filosofía de la Escuela de Frankfurt, que establecen momentos de proximidad y desacuerdo entre los diferentes intelectuales involucrados (Godoy, 112).

Esta plataforma teórica hará coincidir en 1980 la presentación del citado libro de Kay, Del espacio de acá con una publicación experimental de Nelly Richard sobre el cuerpo y la obra de Carlos Leppe, Cuerpo correccional. Esta será una plataforma donde se transferirán modelos teóricos internacionales y que serán problematizados, apropiados y resignificados en relación a la trama histórica local.

En los años sesenta Kay tradujo y comentó los textos El origen de la obra de arte de Martin Heidegger y La obra de arte en la época de su reproductibilidad técnica de Benjamin, siendo un promotor de este pensamiento tras su retorno a Chile, desde las experiencias que mantuvo como parte del Departamento de Estudios Humanísticos de la Universidad de Chile. Como recuerda Adriana Valdés: "Ronald Kay, recién llegado de Alemania, daba a conocer aquí la obra de Vostell. Con él, con Eugenio Dittborn, Enrique Lihn y Catalina Parra nos juntábamos, además, para leer sus traducciones de Walter Benjamin". (Valdés, 279-80). Nelly Richard advierte de la importancia de Benjamin para el escenario chileno de los ochenta, sobre todo en relación a la memoria, por la tensión entre recuerdo y olvido: "Entre latencia y muerte, revelación y ocultamiento, prueba y denegación, sustracción y restitución” (Richard, 14) actúan estas "técnicas de reinvención de memoria", como les llama Richard a una serie de obras artísticas o literarias chilenas. La pensadora continúa, "No es que tales obras les respondieran a los textos de Walter Benjamin (...) desde ya, Benjamin nunca fue parte del corpus de referencias teóricas manejado dentro de la universidad chilena por la crítica literaria de izquierda que lo podría haber acogido". Para ella, la productividad de la fuerza del pensamiento del autor se desplegó fuera de los recintos universitarios y fluyó heterogéneamente; se trataría de obras inspiradas por alianzas o parentescos "que se acordaban secretamente, sin órdenes de programas ni métodos", de una experimentalidad de sentidos en clave rizomática. Estas formas de apropiación de los referentes del Norte global pueden verse en gran parte de la producción artística y literaria y que, experiencias como el seminario de Kay, ayudaron a potenciar, poner en cuestión y problematizar. 
Con la transcripción de este audio, queremos exponer un material inédito para acceder a un momento. El seminario de Ronald Kay se realizó con la traducción que él hizo de los textos de Benjamin. Hemos realizado las transcripciones intentando dar cuenta de parte de los movimientos del pensamiento que se daban allí, de las fugas de palabras, del movimiento del interlocutor e incluso de su distancia de la grabadora de casetes lo que hace, por momentos, inaudible lo que se dice. Movimientos que son parte del mismo registro y otorgan otros silencios. Hemos querido dar cierto tipo de movimiento a esta forma de transcribir, seleccionando algunas partes y registrando algunos diálogos. Sentir que estos audios de cierta manera aún tienen vida propia. La transcripción intenta retomar las ideas más importantes, indicando las partes donde el orador se aleja de la máquina pero algo del sentido es audible. En cursiva se consignan las partes que se han transcrito tal cual como Kay lo lee o explica y algunas preguntas de las y los asistentes.

\section{Escucha de casetes del seminario Walter Benjamin realizado por Ronald Kay en 1981}

\section{Casete 1}

Kay introduce La obra de arte en su época de reproductibilidad técnica a través de un acercamiento a la figura de Bejamin, indicando que este junta varias tradiciones que, dentro del pensamiento occidental, nunca se han juntado. Por un lado, tiene toda la tradición judía, se hace cargo de esa tradición. Por otro lado, es el primer traductor de Prust al alemán. Es un gran conocedor de Valery, de Mallarmé. Es un conocedor absoluto del movimiento Dadá. Está muy a caballo en toda la tradición filosófica alemana: tiene trabajos sobre Kant en su doctorado. Por otro lado, es el primer hombre que junta a Freud con Marx: del materialismo histórico al psicoanálisis. Es el único que se puede considerar un pensador surrealista. Es el único que lleva a su pensamiento los métodos del surrealismo y el Dadá.

Seguidamente, realizará un gesto de aterrizaje del pensador al contexto local, asumiendo las condiciones de un territorio marcado por el colonialismo español a la vez que borrando ciertas ancestralidades que aún viven en dicho contexto: estamos viviendo en un medio, en este continente, en el cual prácticamente no hay algo que se pueda llamar obra de arte o algo que sea propiamente original. Desde la conquista espanola, evidentemente que hubo culturas autóctonas o culturas indígenas, modos de vida absolutamente original, pero estas fueron destruidas. Y para nosotros es absolutamente inaccesible y reconstruible solamente en parte. Lo que después se hizo fue la destrucción, borrar, y vivir prácticamente de este estado. Nuestras prácticas son producto de otra parte.

A continuación comienza la lectura y comentario del texto de Benjamin. En este marco, Kay indicará: lo que tenemos que pensar, y para eso Benjamin sirve, es que 


\section{FIGURA 1}

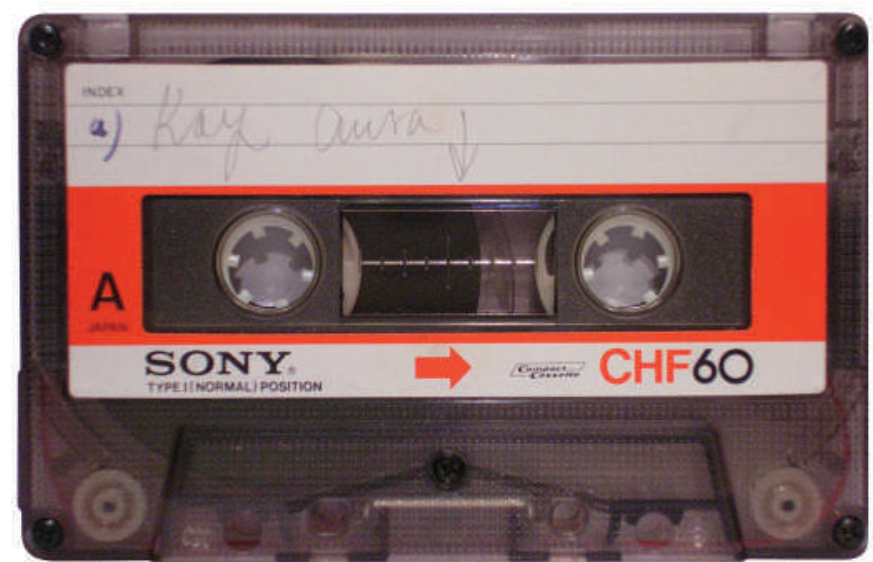

Casete que registra la clase de Ronald Kay sobre el concepto de Aura en Walter Benjamin. Archivo de Luz Donoso

dentro de las relaciones de copia y la reproducción, tiene que haber mecanismos que son positivos. Nosotros estamos acostumbrados a pensar que lo original y lo auténtico es positivo y tiene valor total. Y en ese sentido Benjamin nos permite ver qué mecanismos se ponen en operación en la copia, o lo que él llama la reproducción. En ese sentido es fundamental para mí entender por qué nuestra cultura, nuestras instituciones culturales, la universidad y otras instituciones que representan el pensamiento, todas actúan como si estuviéramos viviendo en una relación original. Y eso no lo hacemos. Aplica paradigmas que provienen de sociedades y relaciones que efectivamente tienen un contacto original con ciertos elementos, entonces nosotros tenemos que desmontar esta maquinaria que no corresponde con la realidad.

En relación al origen del problema de la copia y el original, Kay continuará su análisis de Benjamin indicando que hasta la época de la fotografía solo había un ojo que podía ver, que podemos llamar natural, aunque sea cultural. Pero es un ojo vivo. No había otro ojo que podía mirar el arte. Y el arte, la pintura, era el único ojo que tenía la sociedad. Porque la sociedad solamente podía ver lo que miraba a través de la pintura. Para argumentar esta idea, Kay recurrirá a Karl Marx, quien habría indicado que los cinco sentidos son producto de la historia de la humanidad, complementando Kay que uno no nace con una mano, uno no nace con un oído, sino que se va construyendo.

Para finalizar este análisis histórico, Kay recurrirá al tradicional discurso sobre el renacimiento y la imprenta, en un gesto que recupera la tradición del pensamiento escrito a la vez que olvida la potencia de las tradiciones que se han gestado fuera del sistema escritural: si vemos el paso del lenguaje hablado a la escritura, en la escritura el hombre gana un espacio totalmente distinto. Antes de la escritura, y eso lo llamamos 


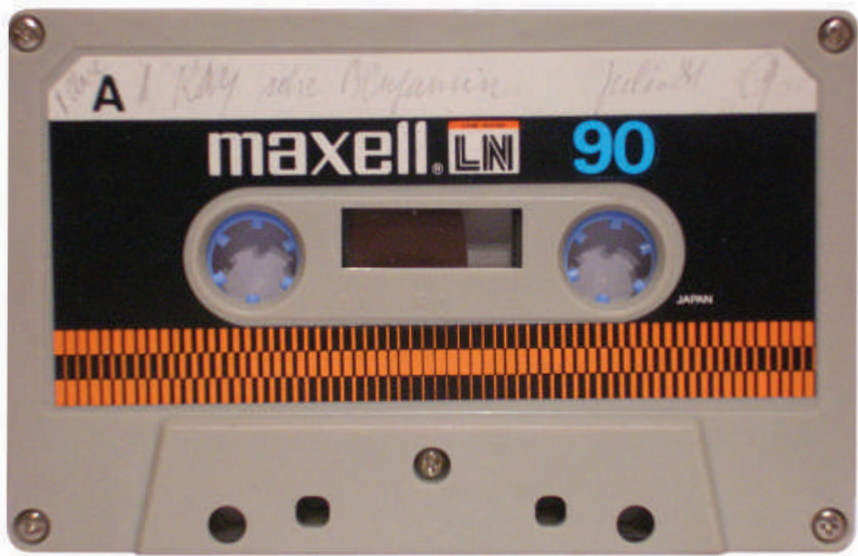

Lado A del casete que registra la primera clase de Ronald Kay sobre Walter Benjamin en julio de 1981. Archivo de Luz Donoso

prehistoria, el hombre no podía hablarle a los muertos. Mientras con la escritura un hombre puede hablarle a los muertos o los no nacidos. Platón será el ejemplo que le permita corroborar cómo su pensamiento ha perdurado debido a la escritura: la escritura es el sistema social que le permite llegar al siglo XIX, al siglo XXV, al siglo XXXX. Termina entonces indicando que, en ese sentido, la escritura es traductor, y la fotografía también que hace una objetivación en un cuerpo social determinado.

\section{Casete 2}

Ronald Kay comenta que el seminario fue mucho más concurrido que lo que él pensaba, pues creía que se podría haber trabajado más específicamente el texto. Además, comenta que no se realizará la última sesión porque él dejará el país a la semana siguiente: entonces este casete corresponde a la última sesión. Kay señala no saber cómo continuar. El avance en la lectura del texto de Benjamin que han hecho hasta el momento solo ha sido de cinco o seis páginas y no se ha podido abordar más. Kay señala: Ha habido preguntas y comentarios que han hecho que yo tenga la cabeza en otras partes. Kay dice conocer el texto muy bien, pero la onda está conectada en varias ondas.

Él propone al grupo que piensen cómo seguir y él tiene una proposición: que la gente que trabajó (leyó el texto) propongan problemas de no comprensión. Dice que el texto es realmente difícil y que intentarlo comprender puede llevar mucho tiempo, mencionando que lleva diez años manejándose con Benjamin. Entonces él propone que se discutan realmente esos problemas específicos de la lectura del texto. 
Segunda opción sería tomar el texto en su totalidad, en algunos puntos cruciales y abordarlos.

Kay aclara que Benjamin, es extremadamente complejo y preciso, entonces, cuando se pierde un matiz, se pierde. A lo que Luz Donoso responde de todas maneras preferimos la última y él responde bueno, esto va a ser difícil, yo les pido ayuda. De todas maneras propongo que veamos la relación de la obra de arte con el lenguaje y la dimensión cultual. Kay lee la parte IV del texto y luego comenta:

Hay dos miradas sociales: una del contexto originario de una obra de arte, que en este caso sería el arte griego, y el traslado de la misma a otro contexto social, sencillamente por el progreso o por el traslado en la historia, en el tiempo, se traslada a otra sociedad. La mirada de otra sociedad sobre la obra da una interpretación distinta y como habíamos visto la sesión anterior, no había otro modo de relacionarse con la obra sino que siempre a través de la mirada de la sociedad, en ese sentido ya habíamos visto cómo la fotografía logra sacarla del contexto social.

Sigue la lectura de Kay y elabora la pregunta ¿Por qué se dice esto: pero a unos y a los otros se le enfrentaba de igual modo su unicidad o dicho con otro término, su aura? Alguien del público responde a lo que Kay señala: Ya, pero ahí estamos viéndolo como si fuera algo subjetivo, en el sentido de que es evidentemente, que una relación social, una situación material, siempre se refleja en la conciencia del sujeto, pero leamos un poco en qué se funda que era la única manera de ver la obra, dado que era única, entre ese objeto único y el sujeto se interponía la mirada de la sociedad que era la interpretación de dos tiempos distintos.

Luego Kay lee otro párrafo y en su comentario se aleja de la grabadora, luego se acerca nuevamente: la sociedad tiene que inocular coactivamente esta relación y el ritual en ese sentido es la forma más festiva donde se conmemora, donde se rememora, se consagra esta relación, para que los sentidos de la sociedad queden ligados a los signos, $y$ en ese sentido podemos entender que este término es del materialismo histórico, el valor de uso de la economía. Esta relación era una relación absolutamente necesaria sobre todo en relación a la crítica que hubo la semana pasada: es que nosotros tenemos que ver que este modo, es decir, que el arte existiera... la humanidad no había inventado hasta ese momento otra forma, entonces es de esta manera que la sociedad se daba sentido, es decir tiene una utilidad esto.

Kay continúa con el último párrafo de la parte iv y comenta: ¿qué es la política acá? Aparece por primera vez en el texto la palabra política y nosotros tenemos que tener en cuenta que seguramente Benjamin en particular con la política...como él está analizando la relación de los sentidos en el cuerpo social y de la organización de los sentidos en una comunidad, la política debe tener que ver con eso, y vamos a tener que dilucidar hasta qué punto la palabra política adquiere un matiz nuevo que no conocemos, y en ese sentido hay algunos indicios en el texto que son muy pocos... el texto es en general un texto político en el sentido en cómo el hombre se relaciona consigo mismo, que es una de las formas más simples de decir lo político. Se había hecho la relación con 
la historia, con la tradición y el rito. Es otra palabra para tradición, que es mantener lo mismo en la sociedad, es desprenderse del rito. A través de la fotografía la obra de arte se desprende, en ese sentido, de la tradición; es decir que tradición y mito son más o menos sinónimo. Ahora viene como un chiste porque en casi todas las traducciones donde aparece la traducción cultual, siempre en vez de poner cultual ponen cultural, hay un error en casi todas las citas de Benjamin, se los digo para que adviertan.

Una mujer del público pregunta: nosotros teníamos que leer ese párrafo, y cuando se habla de la obra seriada, que podrían ser los grabados, ¿los tenemos que considerar como obra única?

Kay responde: no, no, dice Benjamin que el hombre siempre ha podido rehacer lo que ha hecho, el desarrollo de la reproducción, en la seriación de un grabado todavía no estamos en la reproducción de la realidad, de una mirada respecto a otra, porque cuando la fotografía reproduce obras de arte, la fotografía reproduce otra obra en sí misma, lo que no haría el grabado, si no que se reproduce a sí mismo. Pero antes de eso se me ocurrió en la discusión que la palabra seriación no aparece en alemán, es otra palabra.

La mujer del público explica: a nosotros nos surgió la duda porque al ser una obra seriada, como pueden ser el grabado, como puede ser la escultura, correspondería a una obra única.

Kay: sí y no porque, un grabado de Goya, uno sabe que la obra que uno ve está en muchos otras partes: uno participa ya de esta destrucción de la unicidad, pero yo creo que ese no es un problema fundamental: hasta qué punto una obra gráfica de todas maneras no es aurática, ¿por qué tienen ustedes ese problema, cuál es el fundamento de ese problema?

Un hombre del público comenta: (no se escucha muy bien al inicio), el grabado no es una obra única, es una obra seriada, porque una obra única es un objeto único que está en un lugar determinado.

Kay le responde: lo que me llama a mí la atención de la pregunta o lo que yo veo detrás de esa pregunta es rescatar esto todavía para el arte y sepa moya si todavía había que considerar algo en estos términos absolutos como arte, y si vale la pena mantener ese concepto, porque de alguna manera lo que nosotros vemos acá en todo el texto de Benjamin es que la palabra arte es puesta en cuestión, es un fenómeno histórico. La otra obra importante del siglo es El origen de la obra de arte de Heidegger, que es el mejor análisis que hay de la obra aurática: creo que es el mejor intérprete que existe, ese texto es clave, y ustedes deberían leerlo y contrastarlo con Benjamin para ver cómo dos visiones radicalmente antagónicas sí concuerdan en lo aurático. Esa sería la definición de la obra de arte tradicional, pero lo que dice, incluso Heidegger, que el arte muere, no es eterno porque como es una verdad, para él el arte es el desocultamiento de la verdad, de una verdad que es social también. Y las sociedades solamente mantienen durante un periodo ese sentido vivo, entonces el arte muere, quiero decir, que lo interesante acá es cómo en Benjamin desprende el arte como una función progresiva, primero de la magia y luego de la religión. El arte en cuanto tal existe recién desde el renacimiento, 


\section{FIGURA 3}

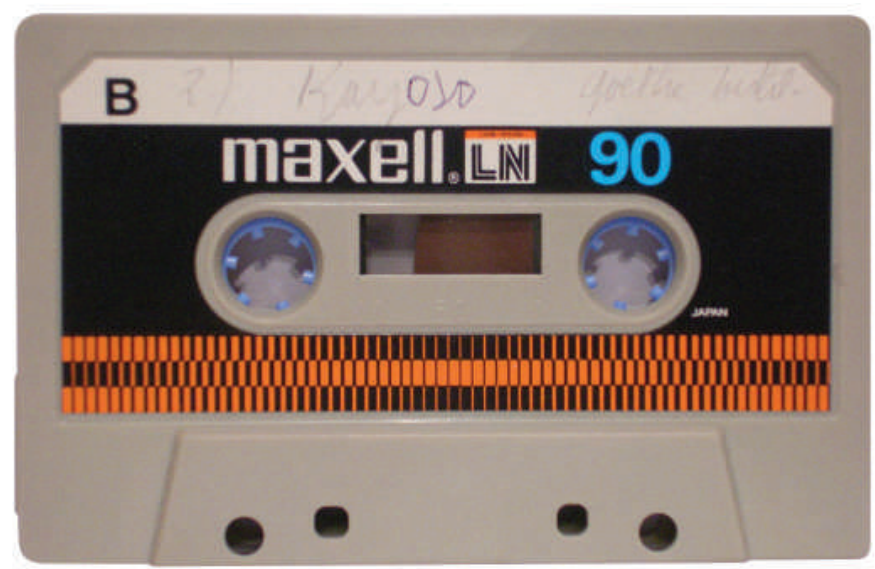

Lado B del casete que registra la primera clase de Ronald Kay sobre Walter Benjamin en julio de 1981. Archivo de Luz Donoso

respecto a la pintura, como los otros valores que introduce en el objeto, las nociones de exposición, de una percepción, de una recepción, en la dispersión, etc., el acercamiento a la cientificidad y a la política. Eso tenemos que seguirlo viendo, que en ese sentido este objeto quizás ya no se llame arte, del mismo modo en que la Madonna era antes meramente religiosa pasó a ser arte y lo que fue arte, nosotros vimos ahora con la mirada distinta que tenemos sobre él, es otra cosa, en ese sentido el término arte, y mantener el aura o quererlo mantener, ya por las relaciones en que estamos, se ha transformado.

Kay continúa: En ese sentido, eso es lo que hay que ver: en qué medida el arte se ha transformado o modificado. El arte no lo podemos mantener con un criterio eterno, en un sentido independiente y autónomo. Todo lo que muestra el texto es cómo se destruye la apariencia de autonomía que el arte tuvo durante ciertas épocas. Cómo podemos entender que la aparición de la fotografía transforma el arte, eso es lo que se pregunta mucha gente todavía hoy día: si la fotografía es un arte, es una pregunta que todavía no ha muerto, este texto es del año 1932 y esa pregunta empezó a surgir en el siglo pasado y todavía sigue vigente, mucha gente dice: ¿la fotografía es un arte y qué es lo que hace esa gente? ¿Cuando tú ves una exposición de fotografía artística qué es lo que ves?

Cuando fotografían un paisaje es una alusión histórica: en el fondo están fotografiando un cuadro. Cuando ven una foto de un muro enconchado, o unos garabatos hechos en la pared, y eso son fotografías de action painting, y también eso es un cuadro, es decir, todo el tiempo están fotografiando cuadros, ¿se dan cuenta? en el fondo antes existió el arte action painting y después alguien busca en la realidad un action painting, eso es lo que pasa. Hay una mirada pictórica que se introduce, se recorta una realidad como si la realidad fuera tomada por la pintura, en ese sentido están fotografiando cuadros, modelos. Entonces ahí se ve la gente que quiere hacer de una fotografía arte: está tergiversando 
la fotografía porque la está usando como si fuera pintura y no como si fuera fotografía. Todos los días estamos viendo las mejores fotografías del mundo sencillamente abriendo el diario La Tercera, el Vea, y todas esas fotografías son propiamente fotográficas. Y en las fotos artísticas de algunos fotógrafos vemos como si estuvieran volviendo hacia atrás, a una mirada anterior a la fotografía.

Pregunta de un hombre del público que no se escucha claramente, solo la última parte donde aborda la cuestión sobre el tamaño de la fotografía, a lo que Kay responde: Sí, eso es muy importante (pequeña parte inentendible). Si ustedes toman una fotografía de este tamaño, de una fotografía de contacto de un negativo del mismo tamaño, si ustedes ven algo y la amplían a tarjeta postal, ustedes ven otra realidad, y si esto estuviera del tamaño de un muro, ustedes ven otra cosa que es totalmente distinta. Hay una película, que es Blow-up, que en la ampliación se ven otras cosas, pero en cualquier toma pasa lo mismo, el tamaño hace que sea algo totalmente distinto, ya una cosa así tiene un carácter de poster, quieren tener una relación distinta con la realidad que una foto $9 \times 12$, que va a circular dentro de un ámbito familiar, va a ser el objeto de recuerdo: esa relación hace que se vea radicalmente diferente el contenido. Si cambia el sentido meramente por el tamaño, tenemos la misma unidad pero el tamaño lo cambia, ¿se dan cuenta del misterio allí? Que la escala, en el caso de la fotografía, es un agente productivo de sentido. Es curioso que ya la transformación a distintas escalas da un sentido distinto, ahora esto es un problema muy interesante de dilucidar, por un lado pasa lo siguiente: nosotros estamos acostumbrados de colocar distintas escalas y darles significados, por ejemplo, el tamaño carnet, la tarjeta postal, tiene un determinado uso, por lo tanto, el uso que se hace de la fotografía es parte de su sentido. Bueno, ahí nos apartamos de Benjamin, pero les he hecho entender lo de la escala que es realmente fascinante.

Volvamos al problema de que si la fotografía es un arte. Es preguntarse por una noción que ya está caduca, en ese sentido preguntarse si un grabado es arte. Tendríamos que pensar cómo plantear eso en términos actuales. Lo que quiero decir es que nosotros de alguna manera privilegiamos la palabra arte, que en alguna medida estamos en un momento todavía retrógrado respecto a las posibilidades de comunicación actuales porque el arte lo valoramos porque somos producto de una educación cultual, y lo valoramos más que los medios de comunicación masiva, cuando decimos arte estamos como privilegiando algo con respecto a otra cosa. Entonces ya ese uso se hace tremendamente sospechoso. Porque privilegiamos una manera de mirar que está muerta, que ya no tiene sentido, ¿qué estamos defendiendo allí ... Es curioso, porque las consignas también son objetos de lucha social, cuando decíamos, en la sesión anterior, que la sociedad es tremendamente pusilánime sobre esta cuestión, ella no quiere que se produzcan cambios, nosotros hemos experimentado en los últimos años en qué punto la palabra democracia, la palabra, Chile, la palabra libertad son objetos de lucha social, que junto a definir eso de una manera distinta significa trastorno social enorme. Se me fue la onda. Ah! Lo que quería decir es que en el campo del arte se ve muy bien 
cómo las distintas posiciones ideológicas dentro de la sociedad quieren apoderarse del ámbito de la tradición. Junto al apoderarse del arte de alguna manera se apodera uno de la tradición y esa es la tentación de las distintas facciones de la sociedad de querer apropiarse del arte, y estas pueden venir de izquierda o de derecha, mientras quedan fuera del campo de la visión, los medios de comunicación masiva que no son tomados en ese sentido como objeto de lucha, o sea no hay interés de los artistas, ya que están fijados en ese objeto donde hay sentido social.

Yo creo que todos ustedes entendieron a cabalidad el párrafo que voy a leer, el párrafo 5, que el valor exhibitivo de la obra de arte aumenta, porque por este sentido analógico del mundo de lo ritual, y la relación cultual, hacían que la obra de arte, en su forma óptima, era estar escondida, muy poco accesible, y creo que eso a ustedes les ha quedado claro, entonces no creo tener que entrar en eso, para ver una cosa que tal vez es más difícil de entender y que da indicios de lo que Benjamin puede decir de lo político. En relación a las fotografías de Atget, un fotógrafo que primero fue un actor $y$ que después se dedicó a fotografiar París de punta a cabo, hizo un archivo de fotografías. Él era un fotógrafo de cajón con una muy buena cámara de cajón, él vendía sus fotos como un fotógrafo... pero el documento, las vitrinas de las casas y las calles sin gente. Salía muy temprano por la mañana y fotografiaba París en esas horas donde las calles están desiertas, están sin gente. Y otra cosa es que es el primer fotógrafo que ve la fotografía como una superficie. Ustedes saben que la fotografía toma con igual detalle todo lo que registra, entonces el lente no privilegia ninguna parte de la fotografía, ocupa la superficie entera con máxima importancia, no privilegia, el fotógrafo puede cercar algo pero la fotografía misma no privilegia nada, el registro es igual, entonces si ustedes ven alguna vez fotografías de él, fíjense en la noción que él tiene de la relación de superficie porque no trata de ver el volumen o el espacio, sino que la traducción de la realidad a la superficie. Entonces él encuentra esto tremendamente importante porque él ve en la fotografía, en las que aparecen personas todavía, se introduce un momento aurático, porque como aparece una persona uno quiere preguntar por último, lo que yo les decía en sesiones anteriores, la tradición en que esa persona existe, la cámara no tiene ninguna relación con esa tradición y ustedes la reproducen al hablar de ella. En ese sentido todavía el hombre reintroduce regresivamente un momento aurático y cultual, por ejemplo, ¿por qué tienen todos ustedes la foto de la polola o del pololo o del hijo o del papá? Porque hay una relación de culto, entonces al no existir personas como objetos fotografiados se puede percibir que la fotografía hace algo muy radical y vamos a tratar de entenderlo.

Kay lee párrafos del libro donde Benjamin se refiere a Atget. Una mujer del público hace un comentario que no se entiende, a lo que Kay responde mientras se aleja de la grabadora de casetes. Después Kay nuevamente se acerca.

¿Por qué puedo decir que este párrafo sea un indicio de lo que es política?, porque no aparece la palabra política, pero ¿En qué sentido puede tomarse? ¿Ustedes pueden ver una fotografía sin hablar? ¿O ustedes han visto alguna vez una fotografía sin comentarla? Una fotografía de Quintana puede servir para ser parte de una propaganda de un 
casco, una fotografía depende del contexto donde se le inserta y adquiere un contenido ¿Alguien tiene una fotografía acá?

Alguien del grupo le entrega una y con ella ejemplifica algunas cuestiones ya mencionadas mientras se aleja de la máquina grabadora de casetes y se termina el audio.

\section{Nuestras voces son producto del espacio de acá}

Esta "escucha sensible" de los audios que registran algunas clases de Kay, nos presenta posibilidades de revitalización de esa memoria en tanto es un material de fuente directa que permite, bajo el registro aural, el análisis del acontecimiento. Quisiéramos proponer desde acá otras conexiones. Así como el estatuto de la fotografía en tanto registro fidedigno de la realidad ha sido discutido, para poner en cuestión el tipo de "verdad" que se presenta, nos interesa ahora proponer una reflexión final sobre la categoría de veracidad y lo que implicaría o posibilitaría para la escritura de la historia del arte, asumiendo un tipo de fuente de registro sonoro, como la que estamos presentando. Lo primero sería pensar cómo el poder del pasado afecta el presente, y cómo el presente afectado resignifica el pasado con conexiones heterogéneas, más allá de ser una fuente cerrada de significados. Para ello, queremos cuestionar la noción cartesiana del conocimiento que se funda en verdades presuntamente científicas, para acceder a sinuosidades más próximas de la oralidad, la escucha o el animismo.

Por otro lado, desde la Bolivia de los años ochenta, el Taller de Historia Oral Andino (тноА), fundado por Silvia Rivera Cusicanqui y otras pensadoras locales, propuso la necesidad de reconstruir y generar un corpus que diese cuenta de la larga memoria oral de ciertos pueblos indígenas, donde el conocimiento no se transmite a través del libro como quiso la colonización, sino que en la experiencia cotidiana entre los seres humanos, las plantas, los animales, los ríos, los lagos, etc. Ese saber de la voz, en su registro, reconstruye las capas de una memoria compleja de dolor, pena y pérdida, pero también de recuperación del pasado frente a las violencias del colonialismo y el racismo. En este sentido, nuestro punto de partida de análisis contradice la idea de Kay de que Desde la conquista española, evidentemente que hubo culturas autóctonas o culturas indígenas, modos de vida absolutamente original, pero estas fueron destruidas.

Considerando estos debates, el título de este artículo presentaría una paradoja: en él, Kay identifica que "nuestras prácticas son producto de otra parte". Dicha aseveración conecta con la propia producción teórica del autor, quien identificaba a la pintura y la fotografía como dispositivos distantes que no pertenecían al continente americano, sino que eran importados. Lo mismo podemos decir de los aparatos teóricos que Kay "ingresa" al debate local, como bien reflejan estos audios en relación a Walter Benjamin. Si este fue un gesto de importación que haría que el hacer americano fuese entendido como una copia, como un aprendizaje eurocéntrico, quisimos aquí situar a 
Kay en contexto. Entender que esa práctica de encuentro y análisis que reviven estos casetes son ejercicios localizados en el marco de opresión de la dictadura militar. Benjamin, entonces, sería una excusa para discutir sobre la propia reproductibilidad de las imágenes en un contexto de muerte y resistencia sudamericano. Ese encuentro colectivo de habla y escucha, como otros que se generaron en ese entonces, sería así un ejercicio "del espacio de acá", que permitía reconstruir pequeñas escenas de comunidad que ayudaban a la supervivencia de la subjetividad.

\section{Referencias}

Galaz, Gaspar. Cuadernos de la escuela de Artes. Santiago de Chile, Editorial de la Pontificia Universidad Católica de Chile, 1997.

Galende, Federico. "Filtraciones I. Conversaciones sobre arte en Chile (de los 60s a los 80s)" Santiago de Chile, Editorial Cuarto Propio, 2007.

----. Filtraciones II. Conversaciones sobre arte en Chile (de los 80s a los 90s) Santiago de Chile, Editorial Cuarto Propio, 2009.

Godoy, Francisco. "Cuerpos que manchan, cuerpos correccionales. Sedimentación y fractura de la escritura de/sobre arte en Chile en 1980". AAVv Ensayos sobre artes visuales. Prácticas y discursos de los años 70 y 80 en Chile, Santiago de Chile, Editorial Cuarto Propio/CEDoc CCPLM, 2012.

Parada, Hernán. “Testimonio de una amistad latente”. En: Varas, Paulina Una acción de otro es una obra de la Luz Donoso. Santiago de Chile, CEAC/Uc, 2011.

Kay, Ronald. Del espacio de acá. Santiago de Chile, Ediciones Nómade, 1980.

Richard, Nelly. "Roturas, memoria y discontinuidades (homenaje a W. Benjamin)". La insubordinación de los signos (cambio político, transformaciones culturales y poéticas de la crisis), Santiago de Chile, Editorial Cuarto Propio, 1994.

Valdés, Adriana. "Algunos textos traducidos". Revista CAL No4. 1979: 23.

Rolnik, Suely. Geopolítica del chuleo, URL:http://eipcp.net/transversal/1106/rolnik/ es/\#_ftn4.

Varas, Paulina. "De la vanguardia artística chilena a la circulación de la Escena de Avanzada”. Papers d'art no 93, 2008.

---. Una acción de otro es una obra de la Luz Donoso. Santiago de Chile, CEAC/Uc, 2011. 